\title{
Empresas Familiares, sucessão e ganhos gerenciais: estudo de caso de empresas de Goiás
}

Arthur Alves Ferreira $^{1}$

Daniela Rosim ${ }^{1}$

Lie Yamanaka ${ }^{1}$

${ }^{1}$ Universidade Federal de Goiás 


\section{EMPRESAS FAMILIARES, SUCESSÃO E GANHOS GERENCIAIS: ESTUDO DE CASO DE EMPRESAS DE GOIÁS}

Resumo: Apesar da representatividade no cenário econômico brasileiro e mundial, o conceito de empresa familiar é bastante discutido, sem um consenso claro entre a comunidade científica. As interações familiares no ambiente empresarial deixam a gestão exposta às particularidades de cada família. No que tange ao processo sucessório, é fundamental que o núcleo familiar se prepare para possíveis dilemas, tanto entre sucessor e sucedido, quanto em relação aos herdeiros não sucessores. Usando uma abordagem qualitativa, o objetivo principal do trabalho foi analisar possíveis ganhos gerenciais de empresas familiares em um processo sucessório. Por meio de um roteiro de entrevista semiestruturada se observou a importância do planejamento da sucessão para a empresa e para a família e dilemas criados a partir deste processo. Como resultados pode-se verificar ganhos obtidos pela sucessão dado que novas gerações, assim que chegam aos cargos de direção, tendem a profissionalizar a gestão das empresas familiares.

Palavras-chave: Empresa familiar. Processo sucessório. Sucessão.

\section{Introdução}

As empresas familiares são grande parte do contexto socioeconômico e cultural brasileiro e internacional, tornando-as destaques dentro da economia e um interessante objeto de estudo para os pesquisadores, em busca de compreender a dinâmica, desafios e peculiaridades presentes nessas organizações. Segundo a PwC (2017), em sua Pesquisa Global sobre empresas familiares, $43 \%$ das empresas familiares do mundo e apenas $19 \%$ das empresas brasileiras tem um plano de sucessão. No entanto esse estudo mostra que, em relação a 2014, a média brasileira praticamente dobrou (saiu de 11\% para 19\%), enquanto a média mundial se manteve quase inalterada. Espalhadas das mais variadas formas e presentes nos mais variados ramos de atuação, elas mantêm sua história e origem ligadas à uma família. Esta ligação com a família, ainda segundo Gersick et al. (1997), faz com que a empresa seja influenciada com fatores temporais, como crises familiares, mortes, doenças e qualquer acontecimento que possa afetar o seio familiar que administra a organização. Uma diferença marcante da empresa familiar em relação às outras empresas se dá pelo fato de existir uma tendência (e vontade por parte da família) de que esta se perpetue na gestão da empresa, gerando um propósito de maior engaje para com a sobrevivência da companhia, que juntamente com um viés passional intrínseco a esse tipo de empresa, pode criar dilemas e conflitos internos que afetam as decisões estratégicas e seu fluxo organizacional (FLORES JR e GRISCI, 2012). Uma das principais causas de

Organizadores:

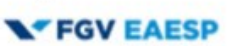

come or
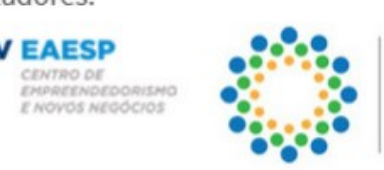

ANEGEPE

Associsctio Nowiond de Estudios

Realizadores:
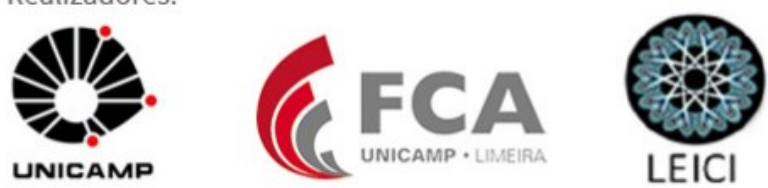
conflitos é decorrente da sucessão de uma geração para outra. Conforme estudo da PwC (2017), apenas $12 \%$ das empresas familiares chegam à terceira geração familiar, corroborando que se trata de um processo delicado e com alto nível de complexidade. Desta forma, torna-se essencial que seja feito um bom planejamento do processo sucessório para que o negócio continue sustentável. A gestão da empresa familiar envolve mitos como a ideia de que o ambiente empresarial deve refletir a imagem de um lar harmonizado, sem conflitos e dilemas (LODI, 1987). No entanto, vários fatores podem colaborar para a alta porcentagem de mortalidade das empresas familiares. Segundo Lank (2003), além de problemas financeiros, as instituições familiares passam por dificuldades também em seus processos sucessórios. São dilemas originários da sucessão: o momento certo para demissão do gestor; a falta de um gestor qualificado na família para ser o sucessor; a dificuldade de aceitação do sucessor escolhido; jogos de poder, onde ser político vale mais que a própria capacidade; falta de planejamento; cultura familiar que influencia negativamente nos negócios; rivalidades entre familiares ou mesmo a rejeição do gestor escolhido ou de suas ideias, são problemas enfrentados pelas empresas familiares na ocasião do processo sucessório, contribuindo para uma alta taxa de mortalidade das mesmas (LANK, 2003).

Os primeiros estudos sobre o conceito de empresa familiar são de Donnelley (1964), que resumia uma empresa familiar em uma instituição que contava com pelo menos duas gerações da mesma família no controle e que, politicamente, esta família ainda tivesse influência. No entanto, conceitos trabalhados principalmente a partir do estudo de Gersick et al. (1997) trouxeram uma visão mais ampla, buscando analisar e descrever o desenvolvimento da organização familiar, o leva a engajar, consequentemente, mais pesquisas cientificas acerca do assunto nas últimas décadas.

Portanto, surgem questões de pesquisa pertinentes, já que a sucessão deve ser analisada como um todo, desde os fatores que levaram ao processo sucessório nas empresas familiares até a sua conclusão, passando pela discussão de como a família fora preparada pelo seu fundador (ou gestor que será sucedido) para atravessar o período da sucessão. Por outro lado, o acervo científico acerca do assunto é escasso e recente (CANÇADO et. al, 2013).

Nesse prisma é relevante analisar o nível de inserção dos sucessores no negócio. Não obstante, a problemática da sucessão engloba os dilemas familiares causados pelo processo, bem como as implicações trazidas à empresa e para seus integrantes em geral. Além disso, é necessário verificar se houve planejamento para a sucessão, e os reflexos em casos afirmativos e negativos desta programação para a organização. Assim surge a seguinte questão: Considerando-se o processo sucessório de maneira mais ampla, quais os ganhos gerenciais para as empresas familiares? Assim, o presente trabalho tem como objetivo ganhos gerenciais de empresas familiares em um processo sucessório, tomando por base o estudo de caso de empresas de Goiás.

\section{Organizadores:}

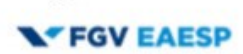

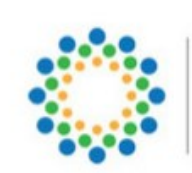

ANECEPE
AEsodiagto N em Emprominatid so Estudios

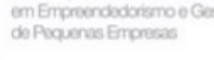
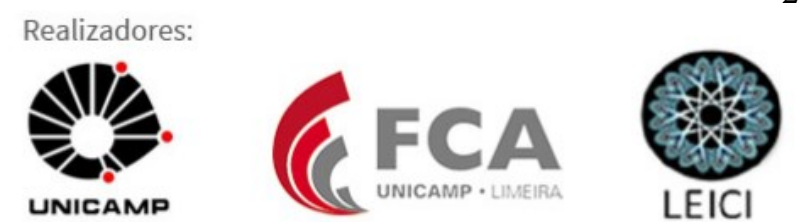


\section{Referencial Teórico}

\subsection{Empresas Familiares}

Empresas familiares formam uma grande parte dos grupos empresariais do Brasil, já chegaram a ser 90\% dos grupos empresariais do país segundo Bethlem (1994 apud MACCARI et. al, 2006), mas com a abertura comercial da década de 90, a exigência de ter uma gestão profissionalizada colocou em risco algumas empresas familiares que acabaram sendo vendidas ou faliram. Segundo Paiva et al. (2008), a produção acadêmica de autores brasileiros sobre as empresas familiares se intensificou ao final dos anos 1990, apesar que já no início da mesma década, foram observados os primeiros estudos sobre o assunto no país, inicialmente voltados para consultorias.

Em ordem cronológica, os primeiros estudos foram focados no controle e na influência familiar, como para Donnelley (1964) e Lodi (1993), que concluem que uma empresa só é familiar se passar para a segunda geração, sendo que sem essa condição, ela seria somente pessoal ou de família. Lodi (1993) diz ainda que o empreendimento de um fundador não pode ser considerado familiar se não houver herdeiros, assim como se uma família apenas investe dinheiro no negócio, ela se torna apenas investidora, e não controladora de uma empresa familiar. Esses autores caracterizam a empresa familiar à luz, principalmente, da propriedade e influência de uma família na organização, ou seja, o controle familiar independe da quantidade de pessoas da família na organização, mas sim do fato de outras gerações assumirem o comando da empresa.

Gallo (1995) colocou três aspectos principais que servem para delimitar as empresas familiares que os autores discutem atualmente: propriedade e controle da família; poder instituído com membros da família na empresa e haver a vontade de sucessão pela família. Com base nessa proposta, autores desenvolveram um plano mais amplo recentemente, como Bueno, Fernández e Sanchez (2007), onde a propriedade da empresa se dá pelo seu número de ações; a gestão se dá pela participação da família na direção e a continuidade pela proporção de familiares na direção e na influência da família na estratégia empresarial.

A partir dos modelos supracitados, outros autores passaram a considerar além das questões de propriedade e da gestão, também o fator familiar, o que implica que no mínimo 
duas pessoas da mesma família devem estar em cargos de alta gestão ou com direito de propriedade, concomitantemente (DAVIS, 2007). Esses três fatores (propriedade, gestão e família) são independentes e diferentes, porém, podem ser superpostos, conforme a figura 1.

O contexto trazido pela figura 1 mostra que qualquer ente participante da empresa familiar pode fazer parte de um dos sete setores, e alguns (intersecções) estão em mais de um setor. Em certo momento da história de uma empresa específica, essa seria uma fotografia da relação empresa/família (FLORES JR e GRISCI, 2012).

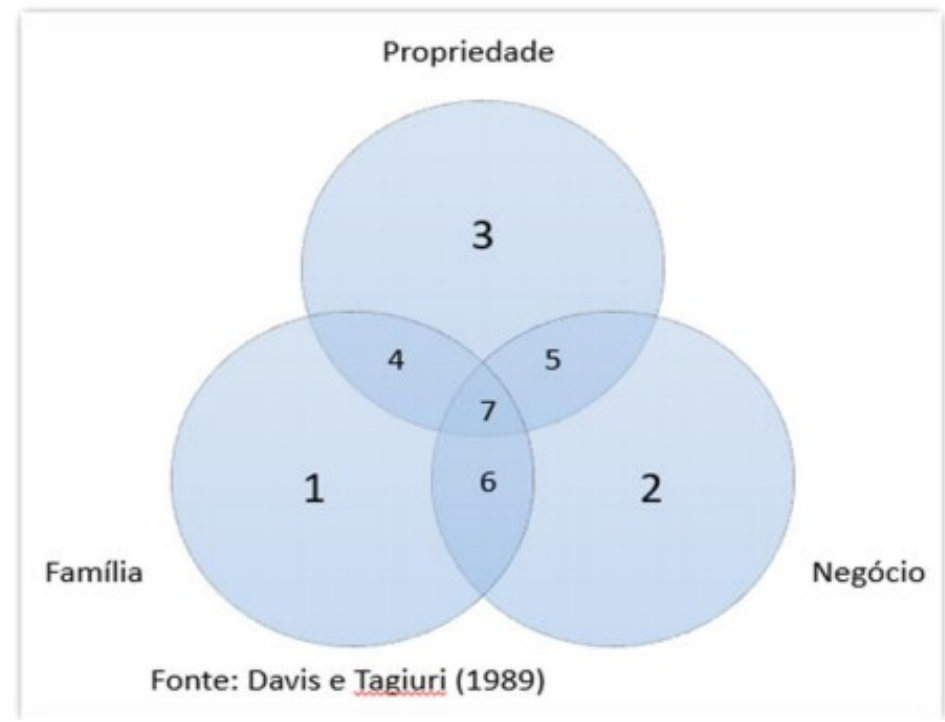

Figura 1 - Modelo de Três Círculos da Empresa Familiar

No entanto, Gersick et al. (1997), concluíram que devido ao dinamismo das organizações, era importante não só localizar onde cada pessoa estava inserida no contexto da empresa familiar, mas também analisar as fases e mudanças de estágio dessas empresas. Para tanto, os autores elaboraram o modelo tridimensional, elencando o desenvolvimento empresarial nos mesmos três eixos de Davis, mas dividindo cada uma dessas dimensões em estágios que simbolizam as fases da organização, de acordo com a figura 2. Tal conclusão não 
só elucida os estágios de desenvolvimento, como também mostra que há possibilidade de empresas em situação de igualdade quanto ao seu porte, ramo, tempo de abertura entre outros, estejam em estágios de desenvolvimento diferentes, graças às individualidades de cada uma, no que tange aos eventos inerentes à família de cada organização (GERSICK ET AL., 1997).

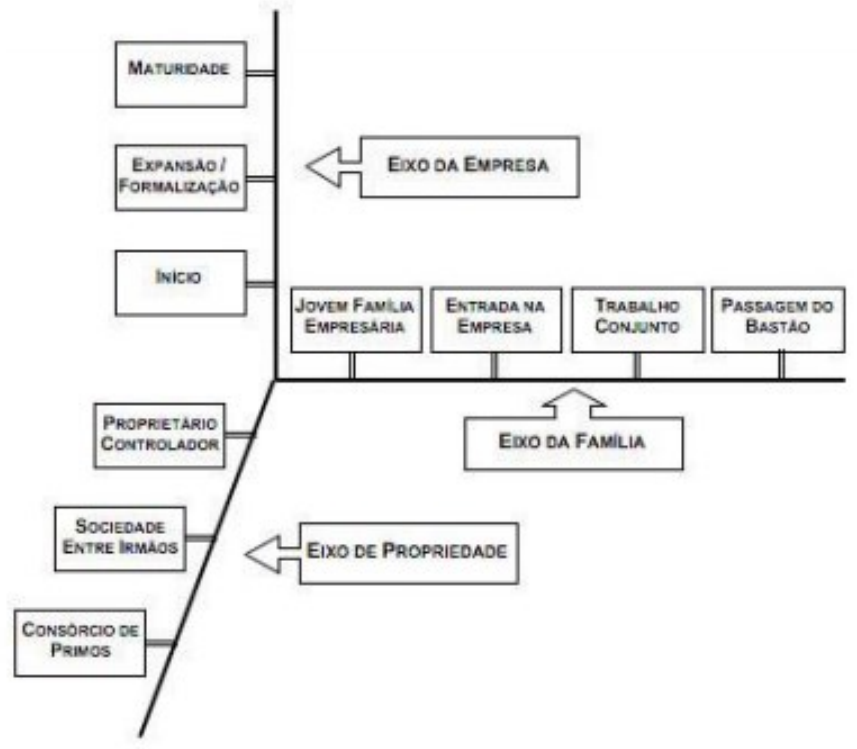

Figura 2 - Eixos do Modelo Tridimensional (GERSICK et al., 1997)

Conforme o quadro 1, o estudo tridimensional mostrou o ciclo de vida das empresas familiares, além de algumas variáveis encontradas quando ocorrem mudanças de estágio em cada um dos eixos. Pela importância dada pelo autor à temática de sucessão neste tipo de empresa, é possível inferir que o processo sucessório está intrínseco às mudanças de estágios de desenvolvimento propostos e suas principais características. Os estágios de desenvolvimento em cada uma das três dimensões (Propriedade, Família e Empresa) são suscetíveis às mudanças em outros eixos, mas continuam sendo independentes por terem seu próprio ritmo e por evoluir de acordo com sua sequência (GERSICK et al., 1997).

No eixo de propriedade, a evolução dos estágios está ligada à geração gestora da empresa, visto que inicialmente há um proprietário controlador ( $1^{\mathrm{a}}$ geração), depois há uma sociedade entre irmãos ( $2^{\mathrm{a}}$ geração) e por fim um consórcio de primos, contemplando a $3^{\mathrm{a}}$ geração em diante. O eixo da família, segundo Gersick et al. (1997) trata da concomitância do trabalho entre os entes familiares na empresa, haja vista que inicialmente existe uma jovem

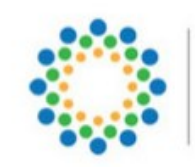


família empresária sem a participação de seus filhos no ambiente empresarial, após essa fase, há entrada na empresa dos seus filhos entre a adolescência e os 30 anos. O terceiro estágio seria o trabalho conjunto entre as gerações, momento em que a geração mais velha tem entre 50 e 65anos e a mais jovem tem entre 20 e 45 anos, já com alguma experiência na rotina da empresa; o quarto e último estágio trata especificamente da sucessão, quando a geração mais velha tem mais de 60 anos e está se preparando para deixar o comando; $\mathrm{O}$ último eixo fala da empresa, onde o início tem uma estrutura organizacional informal, trabalhando em cima de um produto; o segundo estágio fala da expansão dos negócios e o último estágio é o de maturidade, com rotinas organizacionais bem estabelecidas (GERSICK et al., 1997).

\begin{tabular}{c|l|l}
\hline \multicolumn{1}{c|}{ Dimensão } & \multicolumn{1}{|c|}{$\begin{array}{c}\text { Estágio de } \\
\text { desenvolvimento }\end{array}$} & \multicolumn{1}{c}{ Principais características do estágio } \\
\hline \multirow{4}{*}{ Propriedade } & Proprietário controlador & Controle centralizado. \\
\cline { 2 - 3 } & Sociedade entre irmãos & $\begin{array}{l}\text { O controle da empresa é efetivo na geração dos irmãos, estando } \\
\text { dois ou mais irmãos no controle acionário. }\end{array}$ \\
\cline { 2 - 3 } & Consórcio de primos & $\begin{array}{l}\text { Muitos primos são acionistas e há mistura de sócios funcionários e } \\
\text { não funcionários. }\end{array}$ \\
\hline \multirow{4}{*}{ Família } & $\begin{array}{l}\text { Jovem família } \\
\text { empresária }\end{array}$ & $\begin{array}{l}\text { Geração adulta abaixo de 40 anos e filhos, se houver, abaixo de 18 } \\
\text { anos. }\end{array}$ \\
\cline { 2 - 3 } & Entrada na empresa & $\begin{array}{l}\text { A geração mais velha entre 35 e 55 anos e a geração mais jovem } \\
\text { entre a adolescência e os 30 anos. }\end{array}$ \\
\cline { 2 - 4 } & Trabalho conjunto & $\begin{array}{l}\text { Geração mais antiga entre 50 e 65 anos e a geração mais jovem } \\
\text { entre 20 e 45 anos. }\end{array}$ \\
\cline { 2 - 3 } & Passagem do bastão & Geração mais velha com 60 anos ou mais. \\
\hline \multirow{5}{*}{ Empresa } & Início & $\begin{array}{l}\text { Estrutura organizacional informal, com a presença do proprietário- } \\
\text { gerente no centro. Geralmente desenvolve um produto. }\end{array}$ \\
\cline { 2 - 3 } & Expansão/ formalização & $\begin{array}{l}\text { A estrutura fica cada vez mais funcional e desenvolvem-se produtos } \\
\text { ou linhas de negócios múltiplos. }\end{array}$ \\
\cline { 2 - 3 } & Maturidade & $\begin{array}{l}\text { As rotinas organizacionais estão bem estabelecidas, com a estrutura } \\
\text { favorecendo a estabilidade e dirigida pela alta gerência. Base de } \\
\text { clientes estável ou com modesto crescimento. }\end{array}$ \\
\hline \hline
\end{tabular}

Quadro 1 - Estágios do Modelo Tridimensional

Todas as diferentes correntes de pensamento demonstram que não há consenso acerca do conceito de empresa familiar, já que há um distanciamento evidente entre os tipos de definições e, portanto, para fins deste trabalho, será utilizado o conceito de Davis (2007), onde as empresas familiares são aquelas nas quais dois ou mais membros da família exercem sua influência por meio dos seus laços familiares, pelo seu direito de propriedade e pelo próprio cargo gerencial na companhia. 


\section{Métodos de Pesquisa}

Para fins deste trabalho, a pesquisa é do tipo exploratória, pois envolvem estudos de caso com entrevistas semiestruturadas, em empresas e pessoas com experiência no tema abordado. Por fim, a pesquisa exploratória visa gerar maior familiaridade com o assunto tema, com finalidade de torná-lo mais explícito para a sociedade (GIL, 2008).

Quanto à abordagem do trabalho, a pesquisa é qualitativa, que segundo Minayo (2008), deve ter como princípio a objetivação, pois é necessário reconhecer a complexidade do tema, rever suas teorias, usar técnicas de coleta de dados adequadas, para finalmente analisar os dados de forma contextualizada.

Em relação à técnica de pesquisa o presente estudo, utilizou-se o estudo de caso, uma vez que segundo Yin (2001), eles representam o melhor meio de pesquisa quando o pesquisador tem pouco controle sobre os eventos; existem questões do tipo "como" e "por que" e quando a pesquisa está focada em fenômenos contemporâneos dentro de um contexto da sociedade.

O objeto desta pesquisa foi definido como empresas familiares que tenham passado por pelo menos um processo de sucessão durante sua história, individualizando o contexto em que estão inseridas, a fim de comparar os resultados retornados pelo estudo, em momento oportuno.

Os dados inerentes à pesquisa foram coletados através de entrevistas com os gestores de duas empresas familiares, sendo eles diretores nas respectivas instituições.

O método utilizado com os participantes foi uma entrevista semiestruturada com perguntas abertas derivantes de "o que", "por que", "onde", "quando" e "como". Cada entrevista teve duração entre 40 e 60 minutos. Os participantes foram caracterizados no Quadro 2.

Quadro 2 - Informações sobre os entrevistados

\begin{tabular}{|c|c|c|}
\hline \multicolumn{3}{|c|}{ INFORMAÇÕES SOBRE OS ENTREVSTADOS } \\
\hline & ENTREVISTADO 1 (PEDRO*) & ENTREVISTADO 2 (JOÃO*) \\
\hline IDADE & 35 & 35 \\
\hline CARGO & DIRETOR FINANCEIRO & DIRETOR \\
\hline FORMAÇÄO & ADMINISTRADOR & ENGENHEIRO CIVL \\
\hline TEMPO DE EMPRESA & 10 ANOS & 4 ANOS \\
\hline
\end{tabular}

*Nomes fictícios 
As empresas em questão estão em gerações diferentes de comando, característica importante para a análise que objetiva este trabalho, uma vez que será possível identificar se há disparidade gerencial nas empresas que se encontram em níveis familiares distintos.

Por ser uma pesquisa qualitativa, buscando analisar os dados coletados de forma contextualizada (MINAYO, 2008), as entrevistas realizadas foram transcritas para melhor entendimento dos casos estudados. Após a transcrição, os dados obtidos foram separados de acordo com a base teórica discutida previamente, a fim de se alcançar o objetivo definido.

\section{Resultados e Análise dos Dados}

Foram estudadas duas empresas para a realização do trabalho, caracterizadas a partir do Quadro 3.

Quadro 3 - Informações sobre as empresas

\begin{tabular}{|c|c|c|}
\hline \multicolumn{3}{|c|}{ INFORMAÇÕES SOBRE AS EMPRESAS } \\
\hline & EMPRESA1 (MINERADORA & EMPRESA2 (CONSTRUTORA*) \\
\hline RAMO & MINERAÇÃO & ENGENHARIACONSTRUÇÃO \\
\hline FUNDAÇÃO & 1964 & 2002 \\
\hline N$^{*}$ DE FUNCIONÁRIOS & 250 & 50 \\
\hline GERAÇÃO GESTORA & TERCEIRA & SEGUNDA \\
\hline
\end{tabular}

*Nomes fictícios

A empresa Mineradora faz parte de um grupo empresarial reconhecido no cenário goiano, sendo a empresa mãe deste grupo. Atua na área de mineração, no seguimento de materiais britados, desde 1964. Desde sua fundação, diversificou seus investimentos, que constituíram um total de doze empresas, entre pedreiras, fundos de investimentos, agronegócio, venda de produtos asfálticos e aluguel de máquinas. Esse crescimento resultou na formação de um grupo empresarial controlado pela família de Pedro, que conta com aproximadamente 250 colaboradores atualmente.

A empresa foi fundada pelo avô de Pedro, momento em que nenhum outro integrante de sua família fazia parte do quadro diretivo da instituição. Atualmente, seis familiares são gestores (terceira geração), sendo três desses pertencentes ao conselho administrativo do grupo, 
além de quatro sócios acionistas, os quais tem apenas participação financeira. O fundador não faz mais parte da organização.

A empresa está na terceira geração de gestores. Pedro presenciou o primeiro processo sucessório, e participou ativamente do segundo, sendo este implantado recentemente, quando o mesmo se tornou gestor da empresa Mineradora, efetivamente.

A empresa Construtora foi fundada em 2002, atua no ramo da construção civil, com projetos e execução de obras. Apesar de ser mais recente no mercado, está em um viés de alta, dada a quantidade de obras executadas no momento pela companhia, conforme relato de João. Possui um total de cinquenta colaboradores atualmente, sendo cinco deles pertencentes ao núcleo familiar controlador da instituição.

Antes do processo sucessório ocorrido há quatro anos, a empresa era controlada pelo pai de João, que passou a direção para o entrevistado e seus dois irmãos após a sucessão. No entanto, o fundador ainda faz parte da organização, mas sem participar ativamente das decisões gerenciais.

As duas empresas se enquadram na definição de Davis (2007) para empresas familiares, pois em ambas, pelo menos dois membros da mesma família exercem influência na organização através de cargos gerenciais, do seu direito de propriedade e dos seus próprios laços familiares.

Após as sucessões, as gerações que assumem geralmente tomam decisões gerenciais inovadoras para a empresa. Segundo estudo de Estol e Ferreira (2006), de maneira geral, a segunda geração é responsável por inserir a profissionalização da gestão nas organizações familiares. As entrevistas reforçaram essa tese, conforme o Quadro 4.

Percebe-se que a empresa 1 (Mineradora) teve ganhos gerenciais em relação aos seus processos. O fato de estar na terceira geração, após uma grande expansão dos negócios durante a gestão da segunda geração, permite que seus administradores se voltem para um melhor estudo da operação realizada na instituição. Segundo Pedro, ele e os outros gestores de sua geração implantaram um sistema de avaliação dos processos, mapeando o tempo de realização de cada um. Essa avaliação permitiu que os dados fossem comparados interna e externamente, em busca de melhorias no desempenho da organização. Outro ganho gerencial foi atribuir uma maior rigidez ao controle das atividades realizadas, tentando encontrar possíveis erros durante os processos da forma mais rápida possível a fim de reduzir as perdas. 
Quadro 4 - Implicações Gerenciais após os Processos Sucessórios

\begin{tabular}{|c|c|}
\hline \multicolumn{2}{|c|}{ IMPLICAÇÕES GERENCIAIS DOS PROCESSOS SUCESSÓRIOS } \\
\hline EMPRESA1 (3 ${ }^{\text {a Geração) }}$ & EMPRESA2 (2 Geração) \\
\hline Avaliação dos processos operacionais & $\begin{array}{c}\text { Implementação de sistema de gestão e } \\
\text { servidor de arquivos }\end{array}$ \\
\hline Benchmark dos processos & $\begin{array}{c}\text { Controle gerencial a partir de reuniões } \\
\text { mensais }\end{array}$ \\
\hline Maior controle das atividades realizadas & Investimento em infraestrutura \\
\hline Abertura de novos nichos de negócio & Readequação de setores \\
\hline Treinamento dos familiares & Expansão das atividades \\
\hline
\end{tabular}

O gestor afirma, no entanto, que ainda busca novos nichos para investimentos do grupo, mesmo que essa não seja a prioridade no momento. Ele acredita que a aquisição de novas empresas é viável, não só para aumentar o ativo da organização, como para manter o controle da família, pois acredita ser necessário que novos membros da família sejam preparados para serem inseridos no negócio.

É importante ressaltar que é visível a vontade de Pedro em manter a família no negócio, inclusive a decisão de descentralizar a gestão após a segunda sucessão, mostra a intenção de abertura para novas ideias vindas dos familiares. O próprio gestor considera essencial que a empresa se renove em termos gerenciais de tempos em tempos, para continuar crescendo e se consolidando cada vez mais no cenário em que atua.

Em contrapartida, a segunda geração que comanda a empresa 2 (Construtora), teve outras preocupações na dimensão de gestão. João salienta que os principais ganhos gerenciais após a sucessão se dão no âmbito da estrutura, tanto física quanto organizacional. Não obstante, sua principal intenção era diversificar o portfólio e expandir o alcance de sua empresa.

Para tanto, investiu em sistemas de gestão e em um servidor de arquivos, os quais a empresa não possuía. Na parte física ainda expandiu o escritório, criando novas salas, para acomodar melhor os gestores e seus colaboradores. Em termos de estrutura organizacional, 
criou novos setores e diminuiu a quantidade de funcionários em outros, visando uma maior fluidez.

Implementou um controle das obras da empresa, através de reuniões mensais com seus irmãos e com os engenheiros contratados. Segundo o entrevistado, as reuniões são importantes para que os diretores tenham ciência do andamento das obras, uma vez que nem sempre é possível acompanhar todas de perto.

Contudo, na visão do gestor, o maior ganho gerencial foi a expansão através de novos serviços ofertados. Até então, a empresa não trabalhava com loteamentos e obras de engenharia civil, focando em aluguel de máquinas e terraplenagem. Desde essa abertura, o entrevistado enfatiza que a visibilidade e confiabilidade na instituição cresceram, juntamente com seus resultados financeiros.

Após a extração de todos os dados coletados durante as entrevistas é possível identificar em quais estágios de cada eixo do modelo tridimensional de Gersick et al. (1997) cada empresa está atualmente, conforme o Quadro 5. Quadro 5 - Estágio de Desenvolvimento das empresas estudadas em relação ao Modelo Tridimensional de Gerscik et al. (1997).

\begin{tabular}{|c|c|c|}
\hline \multicolumn{2}{|c|}{ ESTÁGIO DE DESENVOLVIMENTO EM RELAÇÃO AO MODELO TRIDIMENSIONAL } \\
\hline EIXOS & EMPRESA1 & EMPRESA2 \\
\hline EMPRESA & MATURIDADE & EXPANSÃO/FORMALIZAÇÃO \\
\hline FAMÍLIA & PASSAGEM DO BASTÃO & TRABALHO CONJUNTO \\
\hline PROPRIEDADE & CONSÓRCIO DE PRIMOS & SOCIEDADE ENTRE IRMÃOS \\
\hline
\end{tabular}

A empresa 1 (Mineradora), em relação ao eixo da empresa, está no estágio de maturidade, uma vez que teve uma grande expansão durante a gestão da segunda geração, e atualmente aprimora suas rotinas gerenciais. No eixo da família, está no estágio de passagem do bastão, pois a geração mais velha (que foi sucedida recentemente) tem mais de 60 anos. Por fim, em relação à propriedade, está no estágio de consórcio de primos, haja vista entre os gestores da terceira geração, dois são primos (netos do fundador).

Já a empresa 2 (Construtora), está em estágios menos avançados, até mesmo por ser mais jovem no mercado. Esta se encontra em estágio de expansão no eixo da empresa, buscando se consolidar no mercado, diversificando seus ramos de atuação. Em relação à família, seuestágio é de trabalho conjunto, já que mesmo após a sucessão, a geração mais velha ajuda a mais nova no trabalho. Consequência de seu único processo sucessório, está no estágio de

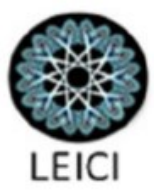


sociedade entre irmãos para o eixo da propriedade, visto que a gestão é feita pelos três filhos do fundador, atualmente.

\section{Considerações Finais}

Através da pesquisa qualitativa aplicada, foi possível contextualizar as empresas estudadas para extrair dos entrevistados as respostas para as questões centrais do trabalho, constituindo um resultado satisfatório. Todavia, em apenas uma das empresas em que o questionário foi aplicado, ocorreram dilemas consideráveis durante o processo sucessório. $\mathrm{Na}$ empresa Construtora, o fato do processo ter ocorrido de forma repentina e sem planejamento, originou atritos entre os herdeiros, especialmente pelo entrevistado não ter trabalhado na organização em questão até a sucessão. Por outro lado, fica clara a importância de se planejar o processo sucessório, onde o futuro sucedido tem extrema importância, preparando seus herdeiros e sua família como um todo, se despindo de qualquer vaidade em prol da continuidade da empresa. O planejamento se mostrou essencial para a empresa Mineradora, já que a mesma se amparou em uma consultoria externa para realizar sua sucessão. Nesse programa, os sucessores foram preparados, bem como os gestores sucedidos também participaram, passando sua experiência e vivenciando o momento com sua família. Para atender o objetivo proposto, analisar as implicações gerenciais, o roteiro de pesquisa contou com perguntas sobre as mudanças implementadas pelos gestores entrevistados quando assumiram posições de diretoria. Pelo momento de cada empresa, foi possível perceber que suas preocupações são diferentes, mas não menos importantes. A primeira empresa, por estar na terceira geração e mais consolidada no mercado, busca aprimorar seus processos organizacionais. Para tal, buscar analisar e comparar seus resultados com outras empresas, para ganhar em tempo e qualidade. Já a segunda empresa, tendo menos tempo no mercado e na sua segunda geração de gestores, investe em melhorar sua estrutura física e organizacional, bem como aumentar o mix de serviços ofertados, dando mais visibilidade e confiabilidade à organização. Estudar empresas em estágios diferentes de sucessão e de estrutura foi fundamental para poder comparar os pontos fortes e fracos que cada uma apresentou durante as entrevistas. Portanto é importante lembrar que as suas diferenças complementaram o estudo para alcançar o que foi proposto previamente pelo trabalho. Em linhas gerais, os objetivos propostos foram alcançados, no entanto, o trabalho mostra limitações, visto que os entrevistados eram somente sucessores, o que impossibilita
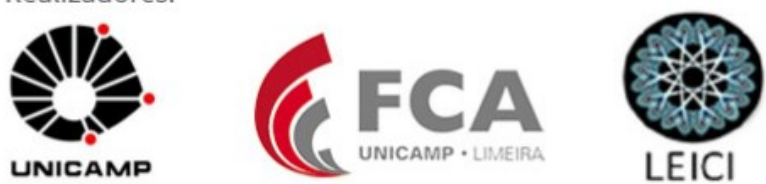
descrever a visão dos sucedidos sobre o processo. A visão das gerações sucedidas seria de fundamental importância, uma vez que seria possível analisar todo o processo, desde a decisão de alçar os herdeiros ao cargo de gestão, até entender como toda a família foi preparada para esse momento. No entanto, a pequena ou nenhuma participação dos sucedidos nas empresas estudadas, inviabilizaram entrevistas com as gerações anteriores. Para as próximas pesquisas, sugere-se que sejam voltadas também para os gestores sucedidos, bem como para os herdeiros não sucessores, ampliando os resultados encontrados. Também é sugestivo categorizar as empresas por segmento ou porte, a fim de encontrar características em comum dos processos sucessórios realizados, sendo importante analisar os impactos para a instituição como um todo, envolvendo colaboradores e stakeholders. 